\title{
Knowledge, attitude and practice of antibiotics: a questionnaire study among 2500 Chinese students
}

Ying Huang 1,3, Jiarui Gu', Mingyu Zhang ${ }^{1}$, Zheng Ren ${ }^{1,2}$, Weidong Yang ${ }^{1,2}$, Yang Chen', Yingmei Fu, ${ }^{1,3}$, Xiaobei Chen ${ }^{1}$, Jochen WL Cals ${ }^{4}$ and Fengmin Zhang ${ }^{1,3^{*}}$

\begin{abstract}
Background: Recently, many scientists including bacteriologists have begun to focus on social aspects of antibiotic management especially the knowledge, attitude and practice (KAP) among the general population regarding antibiotic use. However, relatively few works have published on the relationship between KAP and medical education. In this study, we analyze the present status of Chinese medical (MS)- and non-medical (NS) students' KAP on the use of antibiotics, and examine the influence of Chinese medical curriculum on the appropriate usage of antibiotics among medical students.

Methods: In this study, 2500 students from 3 universities (including one medical university) in Northeastern China participate in the questionnaire survey on students' knowledge, attitude and practice toward antibiotic usage. Wilcoxon rank sum test and Chi square test were used to analyze questionnaire-related discrete and categorical variables respectively, in order to assess the impact of the medical curriculum on students' KAP towards antibiotics.

Results: 2088 (83.5\%) respondents (MS-1236 and NS-852) were considered valid for analysis. The level of knowledge of MS on the proper use of antibiotics was significantly higher than that of NS $(p<0.0001)$. However, based on their responses on actual practice, MS were found to rely on antibiotics more than NS $(p<0.0001)$. Moreover, the knowledge and attitude of MS towards antibiotic use improved with the increase in grade with discriminate use of antibiotics concurrently escalating during the same period.

Conclusions: This study indicates that Chinese medical curriculum significantly improves students' knowledge on antibiotics and raises their attention on antibiotic resistance that may result from indiscriminate use of antibiotics. The study also shows an excessive use of antibiotics especially among the more senior medical students, signifying a deficiency of antibiotics usage instruction in their curriculum. This might explain why there are frequent abuses of antibiotics in both hospital and community settings from a certain angle.
\end{abstract}

Keywords: Anbiotics usage, KAP, Questionnaire survey, Medical students, Statistical analysis

\section{Background}

In 2011, WHO set the theme of World Health Day as 'Combat Antimicrobial Resistance: No Action Today, No Cure Tomorrow' [1]. This shows a serious and global problem of antibiotic abuse and there is a growing consensus to urgently develop new strategies for prevention

\footnotetext{
* Correspondence: fengminzhang@yahoo.com.cn

'Department of Microbiology, Harbin Medical University, 157\# Baojian Road, Nangang Disrict, Harbin, 150081, China

${ }^{3}$ Heilongjiang Province Key Laboratory for Immunity and Infection, Pathogen Biology, Harbin, 150081, China

Full list of author information is available at the end of the article
}

of resistance of bacteria to antibiotics. In recent years, an increasing number of researchers have focused their attention on antibiotic misuse, and follow with interest the knowledge, attitude and practice (KAP) towards antibiotics use of public [2-6].

These surveys reflect the general public's lack of understanding on proper use of antibiotics. Thereby, it reinforces the necessity that establish certain guidelines for public education on the use of antibiotics. Such guidelines would help rationalize public practice in relation to antibiotics use [7,8]. Arguably, the public plays an important

\section{Biomed Central}


role in use (or abuse) of antibiotics as well as the dissemination of these indiscriminate tendencies [9]. Heddini et al., have pointed out that since antibiotics are so widely used in China, the chances of developing drug resistant microbes are much higher, and in their view, what happens in China should also be of great concern to the world [10]. Furthermore, due to the relatively relaxed regulations on antibiotics use in China, it is not difficult to obtain antibiotics without proper prescription (over-the-counter acquisition) [11,12]. Thus, the public knowledge, attitude and practice towards antibiotic use in China warrant greater attention. Besides surveys on the general public, a number of studies have also focused on different cohorts of populations including nurses of day-care centers, parents with infants, internal medicine specialists, dentists and workers in pharmacies [13-17] and others targeting medical students and interns [18-20].

At present, China antibiotic management policy has been released, but the implementation process is not strict. Doctor prescription and self-prescription co-exist. In China, the medical students major in clinical will have prescription right in the future after examination. The clinical courses offered in medical colleges generally provide students knowledge and medicine practice of biomedical bases, diagnosis, treatment, and prevention of diseases. The duration of medical and non-medical is different. Medical profession is generally 5 -year, rather than non-medical profession 4-year. In the 5-year undergraduate study, students do class work in the first three years and hospital-based practice in the final two years. The clinical medicine curriculum gives some introduction of pathogenic microorganisms and infectious diseases, but does not set up antibiotics as a separate entity. Contents related to antibiotic use and resistance is mainly imbedded in chapters of pharmacology and microbiology courses. And the practice of antibiotics prescription is supervised by clinicians during students' clinical internship.

The clinical medical students represent a highly educated group of medical personnel and their knowledge, attitude and behavior in relation to public usage of antibiotics can greatly impact in the future on antibiotic-related issues of China [10]. Distinct with the public-based researches, this study investigates medical (clinical medicine) students' knowledge, attitude and behavior in relation to antibiotic use by controlling with non-medical students. Furthermore, this study also aims at examining the influence of Chinese clinical medicine curriculum on students' knowledge, attitude and practice of antibiotics use.

\section{Methods}

\section{Background of respondents}

Respondents in this study were students from three nation-wide recruit universities in Northeastern China.
All the clinical medicine students (1250) of one representative medical university of Chinese medical education participated in the study. Students from pharmacy, nursing and dentistry programs were not included. Paired 1250 non-medical respondents were randomly selected based on ID number registered in Students' affairs office from the other two universities without clinical medicine course. All the respondents joined in with no incentives and signed the informed consents.

\section{Questionnaire design and grading standards}

The survey was questionnaire-based and the questionnaire is designed for two objectives: to get an overview of the students' understanding of antibiotics, and to compare the MS' and NS' KAP towards antibiotic use, also consider about the differences among grades. Before the main survey, a small-scale pilot study was conducted by a primary manuscript in two universities covering basic questions of antibiotics and their usage. Based on the pilot study, the questionnaire was modified and improved on advice of relevant experts from the field of statistics and epidemiology. The final version of the questionnaire had 30 questions subdivided into four categories: knowledge of antibiotics, attitude towards antibiotic use, perception of public education and practice towards antibiotic use. The questions and the grading standard can be seen in the Additional file 1.

(i) The part on knowledge of antibiotic use had 11 questions covering the normal flora of microbes, concepts of drug sensitivity and susceptibility; relationship of disease, drug resistance, and side effects of antibiotics; views on effectiveness of antibiotics among others. (ii) The part on attitude had 5 questions on the seriousness of antibiotic abuse; its influence on the student and his/her family, and the causes of the abuse. (iii) The part on the perception of perception on public education had 5 questions relating to sources of antibiotics knowledge, information channel, and eagerness to the related knowledge; college course arrangement and proper use of antibiotics campaign. (iv) The part on behavior had 9 questions ranging from the frequency of antibiotic use in fever, illnesses and various other symptoms; understanding of prescription drugs and doctor's prescriptions; drug withdrawal status among others. When compare the overall results of each partitions all questions are concerned.

As shown in the Additional file 1, a common grading standard was used for each question in all the four categories. We graded the answers as 'right' or 'wrong' for the single-answer questions generally considering whether it corresponded with the natural situation. 2 or 0 points were assigned to the 'right' or 'wrong' answers, respectively. For the multiple-answer questions, we assigned 1 point for each 'right' answers and 0 points for the 'wrong' 
ones. A higher score in the first three categories presented better knowledge of antibiotics usage and more positive attitude and perceptions Also, the five-answer questions in the behavior section were graded with 1 point for 'always', 2 for 'often', 3 for 'sometimes', 4 for 'seldom' and 5 for 'never'. A higher score here presented a lower dependency on antibiotics corresponds to better antibiotics usage behavior.

\section{Statistical analysis}

We predefined that a questionnaire was to be considered valid for analysis if $80 \%$ of questions were answered. Wilcoxon rank sum test was used to set the grading scores (as shown above) for discrete variables (such as knowledge, attitude, public perception and behavior/ practice) as well as evaluating whether statistical association exists in the three target groups; such as MS and NS, MS in different grades and NS in different grades. The statistical analyses of categorical variables (such as responses to questions on knowledge, attitude, behavior/ practice and public perceptions) were done using Chi square test to assess the association between medical education and KAP towards antibiotic use. A $p<0.05$ was considered statistically significant. Bonferroni method was employed to do multiple test correction [21]. We also apply Spearman correlation test to estimate the relations of knowledge, attitude and practice. All the analyses were done using statistics software EPIDATA3.1 and SAS9.1.

\section{Results}

\section{Response and data availability}

Of the 2500 questionnaires sent out, 2088 (83.5\%) were considered valid (with $80 \%$ of questions in questionnaire answered) and suitable for analysis. Of these, 1236 firstto fifth-year medical students constituting the main target group, while 852 first- to fourth-year non-medical students were used mainly as control (Table 1 ).

\section{The influence of medical curriculum on MS' knowledge on antibiotic use}

The results show that overall MS scored remarkably better than NS on knowledge of antibiotic use $\left(\chi^{2}=191.8869\right.$, $p<0.0001)$ while no significant difference was found

Table 1 Distribution of 2088 respondents from different universities and grades

\begin{tabular}{llll}
\hline Grade & MS & NS & Total \\
\hline Yr 1 & 262 & 141 & 403 \\
Yr 2 & 244 & 323 & 567 \\
Yr 3 & 216 & 223 & 439 \\
Yr4 & 273 & 165 & 438 \\
Yr 5 & 1 & 241 \\
Total & 241 & 852 & 2088 \\
\hline
\end{tabular}

between first-year MS and first-year NS $\left(\chi^{2}=1.2190\right.$, $p=0.2696$ ). The same pattern of results was observed when answers of each of the questions among MS and NS were analyzed using $\chi^{2}$ test (Table 2). For example, on the question of effectiveness of antibiotics on treating bacterial infection, $92.93 \%$ of MS provided the right answer compared to $81.81 \%$ for NS $(p<0.0001)$. Moreover, $64.52 \%$ of the MS chose 'antibiotics cannot treat viral infection', compared to only $43.44 \%$ among the NS $(p<0.0001)$. At the first-year level there was no striking differences between MS and NS in their knowledge of antibiotics use. However, final year MS had significantly higher scores compared to first-year MS with MS' knowledge improving more appreciably than NS throughout the program (Table 2).

\section{The influence of medical curriculum on MS' attitude and perception of public education}

The results showed that on the questions of attitude on antibiotic use, the MS scored significantly higher than the NS $\left(x^{2}=90.7200, p<0.0001\right)$. A similar pattern was obtained from the analyses of the students' perception of public education $\left(\chi^{2}=40.5875, p<0.0001\right)$. However, when the perception of only first-year students was compared, there was no significant difference between MS and NS in relation to their awareness of public education on antibiotic use $\left(\chi^{2}=0.6291, p=0.4277\right)$. Analysis of responses to each question, found that $82.84 \%$ of the MS believed that drug resistance in bacteria has become a problem in China, and this was much higher than that of NS $(62.80 \%)(p<0.0001)$. Furthermore, $83.88 \%$ of the MS considered abuse of antibiotics was the main cause of drug resistance, while only $61.75 \%$ of the NS did so $(p<0.0001)$. In addition, $81.96 \%$ of the MS and $74.14 \%$ of the NS thought it was necessary to launch certain large scale publicity to promote understanding of antibiotics $(p<0.0001$, Table 3$)$.

\section{The influence of medical curriculum on the MS' behavior towards antibiotics use}

It is interesting to note that our data revealed that MS scored more poorly than the NS on the behavior towards the use of antibiotics. $\left(\chi^{2}=101.2526, p<0.0001\right)$. However, there was no significant difference observed when data from only first-year students from both groups were compared $\left(\chi^{2}=0.0057, p=0.9399\right)$. Moreover, $49.84 \%$ of MS versus $40.02 \%$ of NS advocated use of antibiotics on patients with low fever $\left(<38.5^{\circ} \mathrm{C}\right)(p<0.0001)$ while $13.59 \%$ of MS would use antibiotics with high frequency on common cold compared to $8.45 \%$ of NS ( $p=0.0003$ ). Furthermore, $19.15 \%$ of the MS would actively request doctors to prescribe antibiotics compared with only $12.44 \%$ NS $(p=0.0002)$. When symptoms of respiratory tract infection occur, MS would advocate use of antibiotics more frequently than NS (Table 4). In addition, the 
Table 2 Students' knowledge on antibiotic use

\begin{tabular}{|c|c|c|c|c|c|c|c|c|c|c|c|c|c|}
\hline \multirow[t]{2}{*}{ Question (correct response) } & \multirow[t]{2}{*}{ Total $\%(\mathrm{n} / \mathrm{N})$} & \multicolumn{4}{|l|}{ Whole \% (n/N) } & \multicolumn{4}{|c|}{1 st year $\%(\mathrm{n} / \mathrm{N})$} & \multicolumn{4}{|c|}{ Final year \% (n/N) } \\
\hline & & MS & NS & $x^{2}$ & $p$ & MS & NS & $x^{2}$ & $p$ & MS & NS & $x^{2}$ & $p$ \\
\hline $\begin{array}{l}\text { Can antibiotics cure bacterial } \\
\text { infections? (yes) }\end{array}$ & $88.4(1818 / 2057)$ & $92.9(1130 / 1216)$ & $81.8(688 / 841)$ & 59.87 & $<0.0001^{*} \#$ & $88.2(231 / 262)$ & $85.7(120 / 140)$ & 0.50 & 0.4813 & $93.5(215 / 230)$ & $79.6(129 / 162)$ & 16.96 & $<0.0001^{*}$ \\
\hline $\begin{array}{l}\text { Can antibiotic cure viral } \\
\text { infections? (no) }\end{array}$ & $55.9(1146 / 2050)$ & $64.5(782 / 1212)$ & $43.4(364 / 838)$ & 89.35 & $<0.0001^{*} \#$ & $49.7(130 / 262)$ & $48.2(67 / 139)$ & 0.07 & 0.7871 & $69.1(159 / 230)$ & $39.1(63 / 161)$ & 34.73 & $<0.0001^{*}$ \\
\hline $\begin{array}{l}\text { Do you think the use of } \\
\text { antibiotics will speed up the } \\
\text { recovery of cold, cough? (no) }\end{array}$ & $25.7(531 / 2064)$ & $27.4(333 / 1214)$ & $23.3(198 / 850)$ & 4.48 & $0.0344^{*}$ & $23.1(60 / 260)$ & $19.2(27 / 141)$ & 0.83 & 0.3622 & $31.0(72 / 232)$ & $20.7(34 / 164)$ & 5.20 & $0.0226^{*}$ \\
\hline $\begin{array}{l}\text { Have you heard of antibiotics } \\
\text { resistance? (yes) }\end{array}$ & $91.4(1873 / 2050)$ & $94.7(1146 / 1210)$ & $86.6(727 / 840)$ & 41.88 & $<0.0001 * \#$ & $89.7(235 / 262)$ & $93.6(132 / 141)$ & 1.73 & 0.1879 & $89.2(215 / 241)$ & $78.2(129 / 165)$ & 9.21 & $0.0024^{*}$ \\
\hline $\begin{array}{l}\text { Do you think frequent use of } \\
\text { antibiotics will decrease efficacy } \\
\text { of treatment when using the } \\
\text { antibiotic again? (yes) }\end{array}$ & $84.9(1744 / 2055)$ & $87.9(1063 / 1210)$ & $80.6(681 / 845)$ & 20.42 & $<0.0001^{*} \#$ & $85.8(223 / 260)$ & $83.7(118 / 141)$ & 0.31 & 0.5769 & $85.2(196 / 230)$ & $76.4(123 / 161)$ & 4.90 & $0.0268^{*}$ \\
\hline $\begin{array}{l}\text { Is the efficacy better if the } \\
\text { antibiotics are newer and } \\
\text { more costly? (no) }\end{array}$ & $77.7(1606 / 2066)$ & $81.5(993 / 1219)$ & $72.4(613 / 847)$ & 23.84 & $<0.0001^{*} \#$ & $72.5(190 / 262)$ & $72.9(102 / 140)$ & 0.01 & 0.9423 & $79.3(184 / 232)$ & $70.7(116 / 164)$ & 3.85 & $0.0497^{*}$ \\
\hline
\end{tabular}

${ }^{*} \mathrm{p}<0.05$; \#Significance after multiple test correction. 
Table 3 Students' attitude and public education on usage of antibiotics

\begin{tabular}{|c|c|c|c|c|c|c|c|c|c|c|c|c|c|}
\hline \multirow[t]{2}{*}{ Question (agree) } & \multirow[t]{2}{*}{ Total $\%(\mathrm{n} / \mathrm{N})$} & \multicolumn{4}{|l|}{ Whole \% (n/N) } & \multicolumn{4}{|c|}{ 1st year \% (n/N) } & \multicolumn{4}{|c|}{ Final year \% $(\mathrm{n} / \mathrm{N})$} \\
\hline & & MS & NS & $x^{2}$ & $p$ & MS & NS & $x^{2}$ & $p$ & MS & NS & $x^{2}$ & $p$ \\
\hline $\begin{array}{l}\text { There is abuse on antibiotics } \\
\text { at present. (agree) }\end{array}$ & $86.1(1739 / 2019)$ & $90.1(1069 / 1187)$ & $80.5(670 / 832)$ & 37.19 & $<0.0001^{* \#}$ & $87.2(225 / 258)$ & $76.4(107 / 140)$ & 7.63 & $0.0058^{*}$ & $91.7(200 / 218)$ & $77.9(123 / 158)$ & 14.61 & $<0.0001^{*}$ \\
\hline $\begin{array}{l}\text { Antibiotics resistance has } \\
\text { become a problem in } \\
\text { China. (agree) }\end{array}$ & $74.6(1534 / 2056)$ & $82.8(1004 / 1212)$ & $62.8(530 / 844)$ & 105.50 & $<0.0001^{*} \#$ & $67.2(176 / 262)$ & $52.5(74 / 141)$ & 8.40 & $0.0037^{*}$ & $82.6(199 / 241)$ & $64.8(107 / 165)$ & 16.57 & $<0.0001^{*}$ \\
\hline $\begin{array}{l}\text { Abuse of antibiotics has } \\
\text { become the main cause } \\
\text { leading to bacterial } \\
\text { resistance. (agree) }\end{array}$ & $74.5(1533 / 2059)$ & $83.9(1010 / 1212)$ & $61.8(523 / 847)$ & 122.14 & $<0.0001 * \#$ & $72.9(191 / 262)$ & $65.0(91 / 140)$ & 2.72 & 0.0991 & $81.4(188 / 231)$ & $55.0(89 / 162)$ & 32.01 & $<0.0001^{*}$ \\
\hline $\begin{array}{l}\text { Antibiotic resistance affects } \\
\text { you and your family's health. } \\
\text { (agree) }\end{array}$ & $76.6(1578 / 2059)$ & $81.9(993 / 1213)$ & $69.2(585 / 846)$ & 45.00 & $<0.0001^{*} \#$ & $69.7(182 / 261)$ & 70.7 (99/140) & 0.04 & 0.8377 & $84.4(195 / 231)$ & $63.0(102 / 162)$ & 23.74 & $<0.0001^{*}$ \\
\hline $\begin{array}{l}\text { Necessary to get more } \\
\text { education about antibiotics. } \\
\text { (agree) }\end{array}$ & $85.1(1751 / 2058)$ & $89.2(1082 / 1213)$ & $79.2(669 / 845)$ & 39.47 & $<0.0001^{*} \#$ & $89.3(234 / 262)$ & $80.0(112 / 140)$ & 6.60 & $0.0102^{*}$ & $87.0(201 / 231)$ & $79.5(128 / 161)$ & 3.97 & $0.0464^{*}$ \\
\hline $\begin{array}{l}\text { Need to establish course on } \\
\text { 'rational use of antibiotics' at } \\
\text { university. (agree) }\end{array}$ & $67.3(1388 / 2062)$ & $74.2(901 / 1214)$ & $57.4(487 / 848)$ & 63.95 & $<0.0001^{*} \#$ & $61.1(160 / 262)$ & $61.0(86 / 141)$ & 0.00 & 0.9881 & $74.5(172 / 231)$ & $56.4(92 / 163)$ & 14.03 & $0.0002^{*}$ \\
\hline $\begin{array}{l}\text { Necessary to carry out } \\
\text { large-scale 'antibiotics } \\
\text { campaign' promotion. (agree) }\end{array}$ & $78.8(1623 / 2061)$ & $82.0(995 / 1214)$ & $74.1(628 / 847)$ & 18.21 & $<0.0001^{*} \#$ & $77.5(203 / 262)$ & $74.5(105 / 141)$ & 0.46 & 0.4968 & $82.3(190 / 231)$ & $75.3(122 / 162)$ & 2.80 & 0.094 \\
\hline
\end{tabular}

${ }^{*} p<0.05$; \#Significance after multiple test correction. 


\section{Table 4 Students' behavior of using antibiotic}

\begin{tabular}{|c|c|c|c|c|c|c|c|c|c|c|c|c|c|}
\hline \multirow[t]{2}{*}{ Question (response) } & \multirow[t]{2}{*}{ Total \% (n/N) } & \multicolumn{4}{|l|}{ Whole \% (n/N) } & \multicolumn{4}{|c|}{1 st year $\%(n / N)$} & \multicolumn{4}{|c|}{ Final year $\%(n / N)$} \\
\hline & & MS & NS & $x^{2}$ & $p$ & MS & NS & $x^{2}$ & $p$ & MS & NS & $x^{2}$ & $p$ \\
\hline $\begin{array}{l}\text { Use antibiotics when having fever } \\
\text { (temperature lower than } 38.5^{\circ} \text { ) }\end{array}$ & $45.8(957 / 2088)$ & $49.8(616 / 1236)$ & $40.0(341 / 852)$ & 19.57 & $<0.0001^{*} \#$ & $37.8(99 / 262)$ & $39.7(56 / 141)$ & 0.14 & 0.7041 & $55.6(134 / 241)$ & $38.8(64 / 165)$ & 11.08 & $0.0009^{*}$ \\
\hline Common cold (always, often) & $11.5(240 / 2088)$ & $13.6(168 / 1236)$ & $8.5(72 / 852)$ & 13.11 & $0.0003^{*} \#$ & $10.3(27 / 262)$ & $6.4(9 / 141)$ & 1.73 & 0.1879 & $14.5(35 / 241)$ & $9.7(16 / 165)$ & 2.08 & 0.1496 \\
\hline Acute bronchitis (always, often) & $22.9(479 / 2088)$ & $29.5(364 / 1236)$ & $13.5(115 / 852)$ & 72.60 & $<0.0001^{*} \#$ & $17.6(46 / 262)$ & $14.2(20 / 141)$ & 0.76 & 0.3829 & $39.8(96 / 241)$ & $15.8(26 / 165)$ & 27.01 & $<0.0001^{*}$ \\
\hline $\begin{array}{l}\text { Coughing up yellow/green } \\
\text { sputum (always, often) }\end{array}$ & $27.6(576 / 2088)$ & $37.9(468 / 1236)$ & $12.7(108 / 852)$ & 160.18 & $<0.0001^{*} \#$ & $18.3(48 / 262)$ & $14.9(21 / 141)$ & 0.76 & 0.3837 & $56.4(136 / 241)$ & $12.1(20 / 165)$ & 81.28 & $<0.0001^{*}$ \\
\hline Sore throat (always, often) & $15.3(320 / 2088)$ & $18.9(233 / 1236)$ & $10.2(87 / 852)$ & 29.01 & $<0.0001^{*} \#$ & $14.9(39 / 262)$ & $10.6(15 / 141)$ & 1.43 & 0.2326 & $20.8(50 / 241)$ & $10.9(18 / 165)$ & 6.80 & $0.0091^{*}$ \\
\hline Cough with fever (always, often) & $19.9(415 / 2088)$ & $24.5(303 / 1236)$ & $13.2(112 / 852)$ & 40.93 & $<0.0001^{*} \#$ & $11.5(30 / 262)$ & $12.1(17 / 141)$ & 0.03 & 0.8565 & $28.6(69 / 241)$ & $7.3(12 / 165)$ & 27.98 & $<0.0001^{*}$ \\
\hline $\begin{array}{l}\text { Congested nose with headache } \\
\text { (always, often) }\end{array}$ & $12.5(261 / 2088)$ & $15.0(185 / 1236)$ & $8.9(76 / 852)$ & 16.86 & $<0.0001^{*} \#$ & $9.9(26 / 262)$ & $10.6(15 / 141)$ & 0.05 & 0.8209 & $15.8(38 / 241)$ & $5.5(9 / 165)$ & 10.18 & $0.0014^{*}$ \\
\hline $\begin{array}{l}\text { Coughing up white sputum } \\
\text { (always, often) }\end{array}$ & $9.4(196 / 2088)$ & $10.9(135 / 1236)$ & $7.2(61 / 852)$ & 8.39 & $0.0038^{*}$ & $4.6(12 / 262)$ & $6.4(9 / 141)$ & 0.60 & 0.4374 & $17.8(43 / 241)$ & $9.7(16 / 165)$ & 5.23 & $0.0222^{*}$ \\
\hline $\begin{array}{l}\text { Cough lasting } 2 \text { weeks or more } \\
\text { (always, often) }\end{array}$ & $27.6(576 / 2088)$ & $32.6(403 / 1236)$ & $20.3(173 / 852)$ & 38.20 & $<0.0001 * \#$ & $23.7(62 / 262)$ & $20.6(29 / 141)$ & 0.50 & 0.4782 & $35.7(86 / 241)$ & $18.2(30 / 165)$ & 14.70 & $0.0001^{*}$ \\
\hline $\begin{array}{l}\text { Asked doctors to prescribe } \\
\text { antibiotics when you catch } \\
\text { a common cold (yes) }\end{array}$ & $16.4(335 / 2042)$ & $19.2(231 / 1206)$ & $12.4(104 / 836)$ & 16.99 & $0.0002^{*} \#$ & $9.6(25 / 261)$ & $8.6(12 / 140)$ & 0.11 & 0.7397 & $29.8(68 / 228)$ & $11.5(18 / 157)$ & 18.07 & $<0.0001^{*}$ \\
\hline
\end{tabular}


proportion of MS (75.29\%) who had frequently used antibiotics without the doctor's prescription previous occasions was much higher than that of NS $(49.46 \%)(p<0.0001)$.

\section{Comparison of responses from different grades (academic year) of the medical students}

In order to further explore the influence of the medical curriculum on students' knowledge, attitude and behavior or practice regarding usage of antibiotics at different stages of medical education, we analyzed and compared the responses of MS from different grades with that of NS. The results showed that the answers varied significantly among the MS in different grades. The students' knowledge improved as they progressed in their study attaining the highest scores at third- and fourth-years with a slight decrease in the fifth-year (Figure 1A), suggesting that medical curriculum enhanced their understanding of antibiotics use. Similarly, their attitude on the use of antibiotics was only slightly improved (year 4 ) over the same period with a clearer recognition of antibiotic abuses and development of drug resistance in bacteria (Figure 1B). Figure $1 \mathrm{C}$ shows that the demand for public education to promote the awareness for proper use of antibiotics increased and reaching its peak in 4th year, again with a slight slip-back in the final year. The most surprising, however, was the finding that the MS' score was lower on behavior/practice towards antibiotic use as compared to NS (Figure 1D). There was no significant difference among non-medical students of all grades in terms of their knowledge, attitude and practice towards antibiotics.

\section{Discussion}

This study surveyed MS and NS from three universities in the Northeastern China to assess their knowledge, attitude and practice towards antibiotic use in the form of questionnaires. MS were better than NS in terms of knowledge, attitude and perception on the level of public education on antibiotic use, but worse on behavior. Our study also reveal that the senior MS has a more positive behavior on the usage of antibiotics compared to lower grade MS and NS in general, despite MS would expose to antibiotics education and understand the serious consequences of antibiotic abuse during their earlier years in the medical school.

The result of knowledge studies show that medical students can get more information about antibiotics than other students or public, The increase of knowledge can be well presented by the relative specialized question whether antibiotics can cure viral infection which is described in result partition, whenever it is compared between MS and NS and between grades of MS (69\% of year 5 and $49 \%$ of year 1 ). Some similarity can be drawn from the study in Jordan in 2012 by Suaifan et al. and in 2011 by Shehadeh et al. that highlights existing gaps in the knowledge of MS and NS on antibiotics use [22,23]. The difference, however, lies in the fact that in Jordan self-medication as a result of lack of knowledge on antibiotics plays a leading role in the misuse antibiotics while in China it is the clinicians with the right to prescribe that are at the forefront of antibiotic abuse.

Our study result also prompt that the antibiotic knowledge and attitude education should be strengthened in China. More many MS believed that antibiotics can
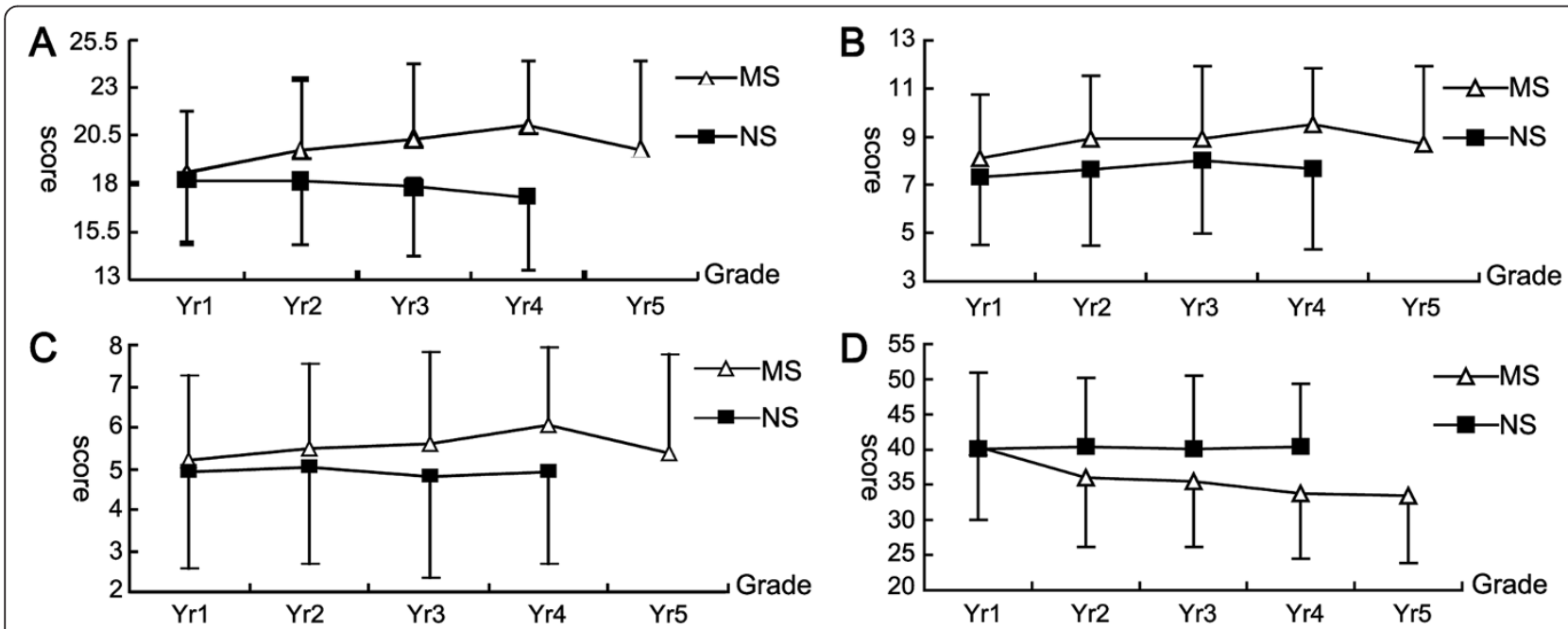

Figure 1 The grading graphs of students' antibiotics knowledge, attitude, practice and views on promotion of understanding of antibiotics. A. Grading graph of students' knowledge in relation to antibiotics. B. Granding graph of students' attitude in relation to antibiotics. C. Granding graph of students' public perception in relation to antibiotics. D. Granding graph of students' practice in relation to antibiotics 
speed up recovery of common cold, cough and a number of other related illnesses arising from viral infections. This is previously an important cause of antibiotic over-use. $74 \%$ of the MS in our study favored the establishment of a course on rational use of antibiotics at university level in China to boost their knowledge level (Table 3). Minen et al. in a KAP survey on antibiotics among 304 MS in America 2010, reported that more than $75 \%$ of the students preferred more education on antibiotics which is consistent with our study (89\%) [18]. According to a research among 503 interns and senior physicians in France, 98\% of physicians considered antibiotic resistance as a national problem, whereas only 83\% of the Chinese medical students shared this view [19] underscoring the great need for sensitization in China.

When we carried about the relationship of knowledge, attitude and behavior, our correlation analysis showed that students' knowledge on antibiotics had a positive correlation with their attitude and awareness of importance of public education, indicating that there was a direct relationship between their knowledge level and attitude towards promotion of public awareness (Spearman correlation coefficient $\mathrm{R}=0.3474, p<0.0001$ ). Our data indicate that there was no direct correlation between the student's knowledge, attitude or public perception and their behavior towards antibiotics use. Today, many countries like Britain and Holland are focusing on public education aimed at changing the irrational and indiscriminate use of antibiotics in the community in order to delaying curtail the development resistance to antibiotics $[9,24]$. Whereas some researchers have reported that public education alone may not necessarily improve the tendency misuse and abuse antibiotics in the society [3], other works argue that providing clear guidelines for medical practitioners may provide a quicker and more effective route to prudent and rational use of antibiotics eventually reversing the current trend $[25,26]$.

We analyze from the level of different grades to research the KAP towards antibiotics use, which is an important feature of our study. Figure 1A, B, C and D show the comparisons between MS' and NS' levels of knowledge, attitude, perception of public education and behavior towards antibiotic use. The MS' knowledge, attitude and perception on antibiotic use improved as they progressed in course peaking at year 4 with a slight scale-back at the year 5 . It is worth noting that the clinical medicine students are introduced antibiotics and antibiotic-related information from the second year in courses such as microbiology (year 2), pharmacology (year 2), internal medicine (year 3), and epidemiology (year 4). Although they could touch prescription of antibiotics during the years 4 and 5, MS do not prescribe any medicines until after they have completed the course. The most senior (years 4 and 5) MS' scores on behavior towards antibiotics use were lower than those of their junior colleagues (years 1,2 and 3) indicating that there could be some negative impact on students' erstwhile good antibiotic practices by the hospital environment during clinical. This fluctuation of KAP could be due to inherent flaws in the medical curriculum. And it reflect that add some courses on rational antibiotic practice in the medical curriculum in China is urgently needed.

This is a large sample size (2500) and high response rate $(83.5 \%)$ research on KAP towards antibiotics usage of MS and NS. And we compare year groups for both MS and NS from representive universities which would reflect the national situation of China, to some extent. On this basis, we propose that it should extra focus on the antibiotic usage and prescription practice introduction of MS in the medical curriculum, and at the same time strengthen the antibiotic knowledge education for MS and public. However, we suggest that future surveys of this nature may endeavor to cover wider geographical regions of the country.

\section{Conclusions}

This survey of $2500 \mathrm{MS}$ and NS reveals that the Chinese medical curriculum significantly improves students' knowledge on antibiotics and antibiotic-related issues. The study also shows an excessive use of antibiotics especially among more senior medical students, reflecting a deficiency of antibiotics usage instruction in their curriculum. This survey also truly reflects some of potential causes of antibiotic abuse in the typical Chinese hospital. To curb the proliferation antibiotic misuse and its consequent effects, we propose the establishment of a special course on rational prescription of antibiotics that emphasizes more on the behavior of medical students towards antibiotics use rather than advance of knowledge alone.

\section{Ethical approval}

All the participants signed the informed consent.

\section{Additional file}

Additional file 1: Questions and the grading standard of the questionnaire.

Competing interests

All authors declare that they have no competing interest.

\section{Authors' contributions}

$F Z, Y H$, JG and YF conceived of the study and participate in its design. MZ, $Z R$ and $W Y$ did the questionnaire survey and collected the data. $Y H, Y C$ and $\mathrm{XC}$ performed the statistical analysis and interpretation of the data. $\mathrm{YH}, \mathrm{YC}$ and FZ drafted the manuscript. JC revised the manuscript critically for 
important intellectual content. All authors read and approved the final manuscript.

\section{Acknowledgments}

This work was supported in part by grants from National Natural Science Foundation of China $(J 0730858,30700032,81101300)$. We also wish to express our sincere thanks to all the students who agreed to participate in this study.

\section{Author details}

'Department of Microbiology, Harbin Medical University, 157\# Baojian Road, Nangang Disrict, Harbin, 150081, China. ${ }^{2}$ The 2nd Affiliated Hospital of Harbin Medical University, Harbin, 150081, China. ${ }^{3}$ Heilongjiang Province Key Laboratory for Immunity and Infection, Pathogen Biology, Harbin, 150081, China. ${ }^{4}$ Department of General Practice, CAPHRI School of Public Health and Primary Care, Maastricht University, Maastricht, Netherlands.

Received: 27 November 2012 Accepted: 3 December 2013 Published: 9 December 2013

\section{References}

1. World Health Day 2011-Antibiotic resistance: No action today, no cure tomorrow. [http://www.who.int/mediacentre/news/statements/2011/ whd_20110407/en/index.html]

2. Andre M, Vernby A, Berg J, Lundborg CS: A survey of public knowledge and awareness related to antibiotic use and resistance in Sweden. J Antimicrob Chemother 2010, 65(6):1292-1296.

3. McNulty CA, Boyle P, Nichols T, Clappison P, Davey P: Don't wear me outthe public's knowledge of and attitudes to antibiotic use. J Antimicrob Chemother 2007, 59(4):727-738.

4. You JH, Yau B, Choi KC, Chau CT, Huang QR, Lee SS: Public knowledge, attitudes and behavior on antibiotic use: a telephone survey in Hong Kong. Infection 2008, 36(2):153-157.

5. Cals JW, Boumans D, Lardinois RJ, Gonzales R, Hopstaken RM, Butler CC, Dinant GJ: Public beliefs on antibiotics and respiratory tract infections: an internet-based questionnaire study. Br J Gen Pract 2007, 57(545):942-947.

6. Panagakou SG, Theodoridou MN, Papaevangelou V, Papastergiou P, Syrogiannopoulos GA, Goutziana GP, Hadjichristodoulou CS: Development and assessment of a questionnaire for a descriptive cross-sectional study concerning parents' knowledge, attitudes and practises in antibiotic use in Greece. BMC Infect Dis 2009, 9:52.

7. Ling Oh A, Hassali MA, Al-Haddad MS, Syed Sulaiman SA, Shafie AA, Awaisu A: Public knowledge and attitudes towards antibiotic usage: a crosssectional study among the general public in the state of Penang. Malaysia. J Infect Dev Ctries 2011, 5(5):338-347.

8. Barah F, Goncalves $\mathrm{V}$ : Antibiotic use and knowledge in the community in Kalamoon, Syrian Arab Republic: a cross-sectional study. East Mediterr Health J 2010, 16(5):516-521.

9. Davey $P$, Pagliari $C$, Hayes $A$ : The patient's role in the spread and control of bacterial resistance to antibiotics. Clin Microbiol Infect 2002, 8(Suppl 2):43-68.

10. Heddini A, Cars O, Qiang S, Tomson G: Antibiotic resistance in China-a major future challenge. Lancet 2009, 373(9657):30.

11. Reynolds $L$, McKee M: Factors influencing antibiotic prescribing in China: an exploratory analysis. Health Policy 2009, 90(1):32-36.

12. Zhang $R$, Eggleston $K$, Rotimi $V$, Zeckhauser RJ: Antibiotic resistance as a global threat: evidence from China. Kuwait and the United States. Global Health 2006, 2:6

13. Hoa NQ, Larson M, Kim Chuc NT, Eriksson B, Trung NV, Stalsby CL: Antibiotics and paediatric acute respiratory infections in rural Vietnam: health-care providers' knowledge, practical competence and reported practice. Trop Med Int Health 2009, 14(5):546-555.

14. Palmer DA, Bauchner H: Parents' and physicians' views on antibiotics. Pediatrics 1997, 99(6):E6.

15. Wester CW, Durairaj L, Evans AT, Schwartz DN, Husain S, Martinez E. Antibiotic resistance: a survey of physician perceptions. Arch Intern Med 2002, 162(19):2210-2216

16. Mainjot A, D'Hoore W, Vanheusden A, Van Nieuwenhuysen JP: Antibiotic prescribing in dental practice in Belgium. Int Endod J 2009, 42(12):1112-1117.
17. Hounsa A, De Mol P: Antibiotics dispensed upon the recommendation of staff in private dispensaries in Abidjan in the Ivory Coast. $J$ Pharm Belg 2009, 3:99-104.

18. Minen MT, Duquaine D, Marx MA, Weiss D: A survey of knowledge, attitudes, and beliefs of medical students concerning antimicrobial use and resistance. Microb Drug Resist 2010, 16(4):285-289.

19. Nyquist AC, Gonzales R, Steiner JF, Sande MA: Antibiotic prescribing for children with colds, upper respiratory tract infections, and bronchitis. Jama 1998, 279(11):875-877.

20. Pulcini C, Williams F, Molinari N, Davey P, Nathwani D: Junior doctors' knowledge and perceptions of antibiotic resistance and prescribing: a survey in France and Scotland. Clin Microbiol Infect 2010, 17(1):80-87.

21. Bland JM, Altman DG: Multiple significance tests: the Bonferroni method. BMJ 1995, 310(6973):170.

22. Suaifan GA, Shehadeh M, Darwish DA, Al-ljel H, Yousef AM, Darwish RM: A cross-sectional study on Knowledge, attitude and behavior ralated to antibiotic use and resistance among medical and non-medical university students in Jordan. Afr J of Pharm Pharmaco 2012, 6(10):763-770.

23. Shehadeh M, Suaifan GA, Darwish RM, Wazaify M, Zaru L, Alja'fari S: Knowledge, attitudes and behavior regarding antibiotics use and misuse among adults in the community of Jordan. A pilot study. Saudi Pharm J 2012, 20:125-133

24. Stille CJ, Rifas-Shiman SL, Kleinman K, Kotch JB, Finkelstein JA: Physician responses to a community-level trial promoting judicious antibiotic use. Ann Fam Med 2008, 6(3):206-212.

25. Metlay JP, Shea JA, Crossette LB, Asch DA: Tensions in antibiotic prescribing: pitting social concerns against the interests of individual patients. J Gen Intern Med 2002, 17(2):87-94.

26. Amabile-Cuevas C: Antibiotic resistance in Mexico: a brief overview of the current status and its causes. J Infect Dev Ctries 2010, 4(3):126-131.

doi:10.1186/1472-6920-13-163

Cite this article as: Huang et al:: Knowledge, attitude and practice of antibiotics: a questionnaire study among 2500 Chinese students. BMC Medical Education 2013 13:163.

\section{Submit your next manuscript to BioMed Central and take full advantage of:}

- Convenient online submission

- Thorough peer review

- No space constraints or color figure charges

- Immediate publication on acceptance

- Inclusion in PubMed, CAS, Scopus and Google Scholar

- Research which is freely available for redistribution 